\title{
A two warehouse deterministic inventory model for deteriorating items with power demand, time varying holding costs and trade credit in a supply chain system
}

\author{
D. Sharmila ${ }^{a^{*}}$ and R. Uthayakumar
}

${ }^{a}$ Department of Mathematics, The Gandhigram Rural Institute-Deemed University, Gandhigram, Tamilnadu, India

\begin{tabular}{l}
\hline C H R O N I C L E \\
\hline Article history: \\
Received March 2, 2017 \\
Received in revised format June \\
10,2017 \\
Accepted July 212017 \\
Available online \\
July 212017 \\
\hline Keywords: \\
Capacity Constraints \\
Deterioration \\
Permissible delay in payments \\
Power demand \\
Varying holding cost
\end{tabular}

\section{Introduction}

Inventory or stock alludes merchandise and materials that a business hold for the inevitable reason for resale (or repair). The extent of stock administration concerns the barely recognizable differences between renewal lead time, conveying expenses of stock, resource administration, stock, determining, stock valuation, future stock value gauging, physical stock, accessible physical space for stock, quality administration, recharging, returns and imperfect merchandise, and request anticipating. Adjusting these contending necessities prompts to ideal stock levels, which is a continuous procedure as the business needs move and respond to the more extensive environment.

Stock administration includes a retailer trying to gain and keep up appropriate wares jumble while requesting, sending, taking care of, and related expenses are held under control. It additionally includes frameworks and procedures that distinguish stock prerequisites, set targets, give recharging systems,

* Corresponding author. Tel. +91-451-2452371, Fax: 91-451-2453071

E-mail address: banadict16@gmail.com uthayagri@gmail.com (D. Sharmila)

(C) 2018 Growing Science Ltd. All rights reserved.

doi: $10.5267 /$ j.uscm.2017.7.002 
report genuine and expected stock status and handle all capacities identified with the following and administration of material. This would incorporate the observing of material moved into and out of stockroom areas and the accommodating of the stock parities. It additionally may incorporate $\mathrm{ABC}$ examination, part following, cycle checking support, and so forth. ABC investigation implies inventory advancement in a production network, $\mathrm{ABC}$ examination is a stock classification, strategy which comprises in isolating things into three classifications, $\mathrm{A}, \mathrm{B}$ and $\mathrm{C}$ : A includes the most important things, while $\mathrm{C}$ covers the minimum profitable ones. This strategy means to draw supervisors' consideration on the basic few (A-things) and not on the paltry numerous (C-items). Inventory streamlining is basic to monitor costs inside the store network. However, keeping in mind the end goal to take full advantage of administration endeavors, it is productive to concentrate on things that cost most to the business. The Pareto rule expresses that $80 \%$ of the general utilization esteem depending on just $20 \%$ of aggregate things. As such, the request is not uniformly disseminated between things: best vendors endlessly outflank the rest.

The $\mathrm{ABC}$ approach expresses that, when looking into stock, an organization ought to rate things from A to $\mathrm{C}$, constructing its appraisals with respect to the accompanying tenets:

4. A-things are products which yearly utilization esteem is the most noteworthy. The main 70$80 \%$ of the yearly use estimation of the organization traditionally represents just $10-20 \%$ of aggregate stock things.

- C-things are, on the unique, things with the most reduced utilization esteem. The lower $5 \%$ of the yearly utilization esteem normally represents half of aggregate stock things.

5. B-things are the inter class things, with a medium use esteem. That $15-25 \%$ of yearly utilization esteem ordinarily represents $30 \%$ of aggregate stock things.

Administration of the inventories, with the essential goal of controlling stock levels inside the physical dispersion framework, capacities adjust the requirement for item accessibility against the requirement for minimizing stock holding and taking care of expenses.

Retailers and wholesalers must oversee autonomous request things that are, things for whose request is affected by economic situations and is not identified with the stock choices for some other things held in stock. Autonomous request stock incorporates discount and retail products, benefit industry stock, end-thing and new parts dispersion inventories, upkeep, repair and working (MRO) supplies. Makers and administration suppliers must oversee subordinate request things that are required as segments or contributions to an item or administration.

Request shifts infrequently, however maker limit is settled. This can prompt to stock aggregation; consider, for instance, how the merchandise expended just on occasions can prompt to gathering of extensive stocks on the expectation of future utilization. We portrayed the request as power request, it might emerge totally toward the end of the period these are the distinctive courses by which the request happens amid a period is named as request example. This circumstance emerges on account of nourishment stuffs, the exceedingly unstable fluids like gas, liquor, radioactive substances like electronic segments, photographic movies and certain other synthetic materials. There might be different wars in which the procedure of weakening may occur amid typical storerooms. It is constantly conceivable to have various courses by which amounts are removed from stock. Every one of these components, which a request happens amid a period is known as request example.

Holding expenses are the expenses connected with putting away stock or resources that stay unsold. Holding expenses are a noteworthy part of the store network administration, since organizations must decide the amount of an item is to be kept in stock. This speaks to an open door cost, as the nearness of the merchandise implies that they are not being sold while that cash could be sent somewhere else. What's more, holding expenses incorporate the expenses of products being harmed or ruined after some 
time and the general costs, for example, space, work and other direct costs. Holding cost, likewise incorporates the open door cost of diminished responsiveness to clients' evolving necessities, moderated presentation of enhanced things, and the stock's esteem and direct costs, since that cash could be utilized for different purposes. The capacity time is partitioned into various particular periods with progressively increment holding costs. As the capacity time reaches out to whenever period, the new holding expense can be connected either retroactively (to all stockpiling periods), or incrementally (to the new period as it were).

\section{Literature Review}

Anand and Kapil (2013) considered variable request rate and time subordinate disintegration. They have taken deficiencies which are completely multiplied. Baker and Urban (1988) worried with the nonstop, deterministic instance of a stock framework in which the request rate was subject to the stock level. Joaquín et al. (2014) proposed to minimize the aggregate cost per stock cycle. This cost relies on two choice factors: the time in which the stock level tumbles to zero and the length of the booking time frame. Likewise numerical cases show the hypothetical results. Joaquin et al. (2013) broke down a stock framework for things with time-fluctuating interest and they additionally talked about the route by which request happens amid the stock cycle takes after a power request design. Likewise the generation of things permits, including stock in the stock amid a renewal period. Teng and Yang (2007) altered the customary EOQ show with steady request and unit cost to take into consideration timeshifting interest and unit buy cost. Patel and Sheikh (2015) built up a stock model for falling apart things with a direct request under factor offering cost. Also, they found that the expansion/diminish in the parameter esteem brings about a relating diminish/increment in the estimation of benefit. Ukil et al. (2015) displayed setting of present day age, without the stock administration cannot think ahead. By the best possible administration and thereby building up the appropriate stock model, the foundation just can spare its creation stock cost. Advertise request dependably changes. Tripathi $(2013,2016)$ exhibited another technique for stock framework with time subordinate request and time subordinate holding cost by considering two cases. Tripathy and Pradhan (2010) built up a stock model for Weibull is falling apart thing with power request design in which deficiencies are permitted and incompletely accumulated. Vipin et al. (2013) built up a deterministic stock model for breaking down environment under the valuation subordinate request with allegorical time fluctuating holding expense and exchange credit.

$\mathrm{Hu}$ and Liu (2010) explored the ideal renewal arrangement under states of reasonable postponement in installments and admissible deficiencies in the monetary generation amount (EPQ) structure. Soni (2013) was worried with the cost displaying of a stock framework with perishable multi-things having stock ward request rates under an inflationary domain of the market. The idea of admissible postponement is considered. Chen and Kang (2010) created, co-ordinated models with passable postponement in installments for deciding the ideal recharging time interim and renewal recurrence. Furthermore, the variation estimating technique is utilized to acquire both sides' cost reserve funds with a specific end goal to allure purchasers to join long haul helpful relationship. Shukla et al. (2010) accepted that the provider would offer the retailer an incomplete allowable deferral in installments when the request amount is less than a foreordained amount (W). What's more, this stock model has been created to make more reasonable and adaptable showcasing approach to the retailer, likewise set up the outcome of the ANOVA investigation by regarding diverse model parameters as components. Bera et al. (2014) researched the retailer's ideal recharging strategy under reasonable postponement in installments. Huang (2016) researched the situation where the retailer's unit offering cost and the buying cost per unit is not really measure up to inside the financial generation amount (EPQ) system under money rebate and passable postponement in installments. 
Musa and Sani (2012) examined around a stock of weakening things where the disintegration starts when the things are supplied. Notwithstanding, there are a few disintegrating things that do not begin breaking down promptly they are held in stock. Chang et al. (2010) exhibited the stock models for crumbling things when the request is a component of the offering cost and stock in plain view. Liao (2007) found the stock recharging approach for falling apart things in which the provider gave an allowable deferral to the buyer if the request amount is more noteworthy than or equivalent to a foreordained amount. Patel and Sheikh (2015) developed an inventory model for deteriorating items with linear demand with different deterioration rates.

Abou and Kotb (1997) gave a straightforward strategy to decide the stock arrangement of various things having shifting holding cost utilizing a geometric programming approach. Dash et al. (2014) displayed in the period, fluctuating holding expense is a direct capacity of time. Furthermore the things (like sustenance grains, design clothes and electronic types of gear) have settled timeframe of realistic usability which diminishes with time amid the end of the season. Bhathavala and Rathod (2012) gave a stock framework stock- subordinate request, in which the holding expense is a diminishing stride capacity of the amount away. Alfares (2007) talked about two sorts of holding cost variety regarding capacity time retroactive increment, and incremental increment. Kasthuri and Seshaiah (2014) exhibited a multi-thing financial generation run estimate the stock model with fluctuating holding expense and request reliant on unit cost without deficiencies under two limitations utilizing KKT conditions technique. Kotb and Fergany (2011) got the systematic arrangement of multi-thing monetary creation run measure stock model with a shifting, holding cost under direct and non-straight requirements which are accepted authoritative. Li et al. (2014) examined a class of stock recreations which emerge when a gathering of retailers who watch interest in a typical thing choose to collaborate and make joint requests with the EOQ strategy. Vinod et al. (2013) considered a deterministic stock model with time-subordinate request and time-fluctuating holding cost where crumbling is time relative. Tripathi et al. (2010) built up a stock model for non-breaking down things over a limited arranging skyline, when the provider gives an allowable deferral in installments.

Sharmila and Uthayakumar (2016) built up a numerical model of a stock framework in which request contingent on stock level and time with different degree, gives more adaptability of the request example and more broadly to the study done as such far with the condition to minimize the aggregate normal cost of the framework. Sharmila and Uthayakumar (2016) examined an ideal stock model for disintegrating things having stock and time subordinate request under the impacts of weakening. Sharmila and Uthayakumar (2015) displayed fluffy stock model for breaking down things with deficiencies under completely accumulated condition. Sharmila and Uthayakumar (2015) inspected the incomplete exchange credit financing in a storage network by EOQ-based model for breaking down things together with deficiencies. Shah and Urmila (2016) considered a producer, retailer stock model for decaying thing under safeguards innovation speculation, with offering cost and two level exchange credit financing. Chowdhury et al. (2016) proposed an ideal stock renewal arrangement for a crumbling thing. As a rule, specialists consider an equivalent recharging cycle. Geetha and Udayakumar (2015) talked about a practical stock model for non-immediate disintegrating things with the cost and ad subordinate nature of interest. Smrutirekha and Milu (2016) built up a financial request amount demonstrate in view of joint cost and time subordinate include with non-immediate falling apart things with non-zero lead time. Tripathi et al. (2017) examined the similar study between aftereffects of the without lock case and with lack case. Mishra (2016) proposed in which request rate as a capacity of stock level and offering cost where the weakening rate has been considered to takes after two parameters Weibull weakening. Tripathy (2016) created ideal requesting arrangements for a retailer when a client request is value subordinate in which provider offers two diverse dynamic credit periods. Mishra (2015) displayed a stock model of direct application to the business ventures that consider the way that the capacity thing is weakened amid capacity periods and in which the request, crumbling, and holding cost rely on the time. 


\section{Methods}

The accompanying notation and assumption will be utilized all through the entire paper.

\subsection{Notation}

OW Own warehouse

RW Rented warehouse

D Demand rate per unit time

$\left(a b^{n}\right.$ where and bareinegersand $\left.\mathrm{n}=0,1,2, \ldots\right)$

A Replenishment cost per order

W Storage capacity of the own warehouse

$\mathrm{T} \quad$ Length of replenishment cycle

Q Order quantity per replenishment

s $\quad$ Selling price per unit item

c Purchasing cost per unit item

$\mathrm{h}_{0} \quad$ Holding cost per unit per unit time in $\mathrm{OW}$

$\left(h_{0}=\mathrm{u}+\mathrm{vt}\right.$ where $\mathrm{u}$ and $\mathrm{v}$ are variables $)$

$\mathrm{h}_{\mathrm{r}}$

Holding cost per unit per unit time in RW $h_{r} \geq h_{0}$

$\left(h_{r}=\mathrm{x}+\mathrm{yt}\right.$ where $x$ and $y$ are variables)

$\mathrm{a}_{1}$

Deterioration rate in $\mathrm{OW}$, where $0<a_{1}$

$b_{1}$

Deterioration rate in $\mathrm{RW}$, where $0<b_{1}$ and $b_{1}>a_{1}$

$\mathrm{T}_{\mathrm{w}}$

Time at which the inventory level reaches zero in RW

$\mathrm{I}_{\mathrm{o}}(\mathrm{t})$

Inventory level in OW at time $\mathrm{t}$

$\mathrm{I}_{\mathrm{R}}(\mathrm{t})$

Inventory level in RW at time $\mathrm{t}$

$\mathrm{I}_{01}(\mathrm{t})$

Level of inventory at OW during the time interval $\left(0, T_{w}\right)$

$\mathrm{I}_{02}(\mathrm{t})$

Level of inventory at OW during the time interval $\left(T_{w}, T\right)$

$\mathrm{T}_{\mathrm{w}}$

Time at which the inventory level reaches zero in RW

$\mathrm{M}$

Permissible delay in settling the accounts

$\mathrm{I}_{\mathrm{P}}$

Interest charged per dollar in stocks per year

$\mathrm{I}_{\mathrm{e}}$

Interest earned per dollar per year 
2.2. Assumption

1. Demand rate is known and it is denoted by a power demand function $\left(a b^{n}\right.$ wherea and $\mathrm{b}$ areinegersand $\left.\mathrm{n}=0,1,2, \ldots\right)$

2. Shortages are not allowed

3. The time horizon is infinite

4. Replenishment rate is infinite and the lead time is zero

5. The owned warehouse (OW) has a fixed capacity of $\mathrm{W}$ units

6. The rented warehouse (RW) has unlimited capacity

7. The items of RW are consumed first and next the items of OW

8. When $T \geq M$, the account is settled at $\mathrm{T}=\mathrm{M}$. Beyond the fixed credit period, the retailer begins paying the interest charges for the items in stock at rate $\mathrm{I}_{\mathrm{p}}$. Before the settlement of the replenishment account, the retailer can use the sales revenue to earn the interest at annual rate $\mathrm{I}_{\mathrm{e}}$, where $I_{p} \geq I_{e}$

9. When $T \leq M$ the account is settled at $\mathrm{T}=\mathrm{M}$ and the retailer need not pay any interest charge. Alternatively, the retailer can accumulate revenue and earn interest until the end of the trade credit period.

\section{Model Formulation and solution}

The issue of this article to be discussed is the way by which the retailer knows paying little respect to whether to rent the RW to hold more things under the conditions of acceptable delay in portions. With the assumptions and notations, when the demand sum, the stock level channels at the time as a consequence of intrigue and deterioration at $\mathrm{OW}$. Therefore, the differential condition addressing the stock level at time $t$ can be made as

$$
\frac{d I_{o}(t)}{d t}+a_{1} I_{o}(t)=-a b^{n} ; 0<t<T, n=0,1,2,3, \ldots
$$

with the boundary condition $I_{o}(T)=0$

$$
I_{o}(t)=\frac{a b^{n}}{a_{1}}\left[e^{a_{1}(T-t)}-1\right] ; 0<t<T, n=0,1,2,3, \ldots
$$

Thus $I_{o}(0)=Q$

$$
\text { which implies that } Q=I_{o}(0)=\frac{a b^{n}}{a_{1}}\left[e^{a_{1} T}-1\right] \text {. }
$$

Then again, when the request amount $\mathrm{Q}>\mathrm{W}$, the stock level at RW diminishes because of decay and interest for a period Tw until it achieves zero. At that point a part of the stock level at OW is exhausted because of the disintegration. Amid the time interim $\left(T_{w}, T\right)$ the stock level at OW gets exhausted as an aftereffect of the consolidated impact of interest and crumbling until time $\mathrm{T}$. As portrayed over, the variety of $\operatorname{IR}(\mathrm{t})$ regarding time is administered by the accompanying differential condition: 


$$
\begin{aligned}
& \frac{d I_{R}(t)}{d t}+b_{1} I_{R}(t)=-a b^{n} ; \\
& 0<t<T_{w}, n=0,1,2,3, \ldots
\end{aligned}
$$

With boundary conditions $I_{R}\left(T_{w}\right)=0$

The solution of this equation is,

$$
\begin{aligned}
& I_{R}(t)=\frac{a b^{n}}{b_{1}}\left[e^{b_{1}\left(T_{w}-t\right)}-1\right] ; \\
& 0 \leq t \leq T_{w}, n=0,1,2,3, \ldots
\end{aligned}
$$

The variation of $I_{01}(t)$ with respect to time is governed by the following differential equation

$$
\frac{d I_{01}(t)}{d t}=-a_{1} I_{01}(t) ; 0<t<T_{w}
$$

Using the boundary condition $I_{01}(0)=W$ we get

$$
I_{01}(t)=W e^{-a_{1} t} \text {. }
$$

Amid the time interim $\left(T_{w}, \mathrm{~T}\right)$ the variety of as of the time is ascertained utilizing the accompanying differential condition

$$
\begin{aligned}
& \frac{d I_{02}(t)}{d t}+a_{1} I_{02}(t)=-a b^{n} ; \\
& T_{w}<t<T, n=0,1,2,3, \ldots
\end{aligned}
$$

By using the boundary condition $I_{02}(T)=0$, we get,

$$
I_{02}(t) e^{a_{1} t}=-\frac{a b^{n} e^{a_{1} t}}{a_{1}}\left[e^{a_{1}(T-t)}-1\right]
$$

Besides because of continuity

$I_{01}\left(T_{w}\right)=I_{02}\left(T_{w}\right)$ We obtain

$$
W e^{-a_{1} t}=\frac{a b^{n}}{a_{1}}\left[e^{a_{1}\left(T-T_{w}\right)}-1\right] .
$$

Eq. (10) implies that

$$
T_{w}=\frac{1}{a_{1}} \log \left(\frac{a b^{n} e^{a_{1} T}-a_{1} W}{a b^{n}}\right) .
$$

Tw is an element of T. Taking the primary request subordinate of $T_{w}$ with deference $\mathrm{T}$ yields

$$
\frac{d T_{w}}{d T}=\frac{d}{d T}\left(\frac{1}{a_{1}} \log \left(\frac{a b^{n} e^{a_{1} T}-a_{1} w}{a b^{n}}\right)\right)
$$

Which implies that

$$
\frac{d T_{w}}{d T}=\frac{a b^{n} e^{a_{1} T}}{a b^{n} e^{a_{1} T}-a W}>1 .
$$


Finally, during the replenishment cycle the order quantity follows the condition is

$Q=I_{R}(0)+I_{01}(0)$

which implies that

$$
\frac{a b^{n}}{b_{1}}\left[e^{b_{1} T_{w}}-1\right]+W
$$

Specifically by equation (3), if we denotes $T_{a}=\frac{1}{a_{1}} \log \left(1+\frac{a_{1} W}{a b^{n}}\right)$ then the inequality $Q \leq W$ holds iff $T \leq T_{a}$ likewise if we denote $M^{*}=\frac{1}{a_{1}} \log \left(\frac{a b^{n} e^{a_{1} M}+a_{1} W}{a b^{n}}\right)$ then the inequality $M \geq T_{w}$ holds iff $M^{*} \geq T$. Therefore we find that $T_{a}<M^{*}$. Additionally since $e^{a_{1} M^{*}}=e^{a_{1} M}+\left(\frac{a_{1} W}{a b^{n}}\right)$ which implies that $M^{*}>M$. From the assumption of, we obtained that $T_{a}<M<M^{*}$. Later the total annual relevant cost can be divided in to two cases $\left[\right.$ Case(i) $T_{a}<M$ and Case(ii) $\left.T_{a} \geq M\right]$; these components are evaluated as follows:

1. Annual ordering cost $\frac{A}{T}$

2. Annual stock holding cost in the RW is derived as follows

Case (i) $T \leq T_{a}$

For this situation, the retailer stores their requested amount of items in the OW, and the RW stays unused. Accordingly, no stock holding costs apply for things in RW.

\section{Case (ii) $T>T_{a}$}

For this situation, the retailer must lease an extra distribution center to store units surpassing the limit of OW, along these lines

Annual stock holding cost in the RW

$$
R W=\int_{0}^{T_{w}} \frac{(x+y t)}{T} I_{R}(t) d t=\frac{a b^{n}}{b_{1} T}\left[\frac{x e^{b_{1} T_{w}}}{b_{1}}+\frac{y e^{b_{1} T_{w}}}{b_{1}^{2}}-\frac{x}{b_{1}}-x T_{w}-\frac{y T_{w}^{2}}{2}-\frac{y T_{w}}{b_{1}}-\frac{y}{b_{1}^{2}}\right] .
$$

3. Annual stock holding cost in the $\mathrm{OW}$ is derived as follows:

Case (i) $T \leq T_{a}$

Annual stock holding cost of the

$$
O W=\int_{0}^{T} \frac{(u+v t)}{T} I_{o}(t) d t=\frac{a b^{n}}{a_{1} T}\left[\frac{-u}{a_{1}}-u T-v\left(\frac{T}{a_{1}}+\frac{1}{a_{1}^{2}}\right)-\frac{v T^{2}}{2}+\frac{u e^{T}}{a_{1}}+\frac{v e^{a_{1} T}}{a_{1}^{2}}\right]
$$

\section{Case (ii) $T>T_{a}$}

Annual stock holding cost in 


$$
\begin{aligned}
& O W_{1}=\int_{0}^{T_{w}} \frac{(u+v t)}{T} I_{01}(t) d t+\int_{T_{w}}^{T} \frac{(u+v t)}{T} I_{02}(t) \\
& =\frac{u W}{T a_{1}}-\frac{u W e^{-a_{1} T_{w}}}{T a_{1}}-\frac{v W}{T}\left[\frac{T_{w} e^{-a_{1} T_{w}}}{a_{1}}+\frac{e^{-a_{1} T_{w}}}{a_{1}^{2}}\right]+\frac{v W}{T a_{1}^{2}}-\frac{u a b^{n}}{T a_{1}^{2}}-\frac{u a b^{n}}{a_{1}} \\
& +\frac{u a b^{n}}{T a_{1}^{2}}\left(e^{a_{1}\left(T-T_{w}\right)}\right)+\frac{u a b^{n} T_{w}}{T a_{1}}+\frac{v a b^{n}}{T a_{1}}\left[-\frac{T}{a_{1}}-\frac{1}{a_{1}^{2}}+\frac{T_{w} e^{a_{1}\left(T-T_{w}\right)}}{a_{1}}+\frac{e^{a_{1}\left(T-T_{w}\right)}}{a_{1}^{2}}-T-T_{w}\right]
\end{aligned}
$$

4. Annual purchasing cost is obtained as follows

Case (i) $T \leq T_{a}$

Annual purchasing cost $=\frac{c Q}{T}=\frac{c}{T}\left[\frac{a b^{n}}{a_{1}}\left(e^{a_{1} T}-1\right)\right]$

Case (ii) $T>T_{a}$

Annual purchasing cost $=\frac{c Q}{T}=\frac{c}{T}\left[\frac{a b^{n}}{b_{1}}\left(e^{b_{1} T_{w}}-1\right)\right]+W$

5. The interest payable per year can be divided into two situations as follows:

Case (i) $T \leq M$

Annual interest earned $=\left(a b^{n}\right) I_{e}\left(M-\frac{T}{2}\right)$

Case (ii) $M<T$

Annual interest earned $=\frac{\left(a b^{n}\right) I_{e} M^{2}}{2 T}$

6. The interest payable per year can be divided as follows:

Case (I) $T_{a}<M$

Case (i) $T<T_{a}$

In this case, no interest charges are paid for the items.

Case (ii) $T_{a}<T \leq M$

In this case, no interest charges are paid for the items.

Case (iii) $M<T \leq M^{*}$

$$
\begin{aligned}
\text { Annual interest payable } & =\frac{c I_{p}}{T} \int_{M}^{T} I_{02}(t) d t=\frac{c I_{p}}{T} \int_{M}^{T} \frac{a b^{n}}{a_{1}}\left[e^{a_{1}(T-t)}-1\right] d t \\
& =\frac{c I_{p}}{T}\left(\frac{a b^{n}}{a_{1}}\right)\left(\frac{e^{a_{1}(T-M)}}{a_{1}}+M-\frac{1}{a_{1}}-T\right)
\end{aligned}
$$

Case (iv) $M^{*}<T$ 


$$
\begin{aligned}
& \text { Annual interest payable }=\frac{c I_{p}}{T} \int_{M}^{T} I_{R}(t) d t+\int_{M}^{T_{w}} I_{01}(t) d t+\int_{T_{w}}^{T} I_{02}(t) d t \\
& =\frac{c I_{p}}{T}\left(\frac{a b^{n}}{b_{1}}\right)\left[\left(\frac{e^{b_{1}\left(T_{w} M\right)}}{b_{1}}\right)-\frac{e^{b_{1}\left(T_{w}-T\right)}}{b_{1}}+M-T\right]+\frac{W e^{-a_{1} M}}{a_{1}}-\frac{W e^{-a_{1} T_{w}}}{a_{1}}+\frac{a b^{n}}{a_{1}}\left[\frac{e^{a_{1}\left(T-T_{w}\right)}}{a_{1}}-\frac{1}{a_{1}}-T+T_{w}\right]
\end{aligned}
$$

Case (II) $T_{a} \geq M$

Case (i) $T_{a} \geq M$

In this case, no interest charges are paid for the items

Case (ii) $M<T \leq T_{a}$

$$
\text { Annual interest payable }=\frac{c I_{p}}{a_{1}^{2}}\left(\frac{e^{a_{1}(T-M)}}{a_{1}}+M-\frac{1}{a_{1}}-T\right)
$$

Case (iii) $T_{a}<T \leq M^{*}$

$$
\text { Annual interest payable }=\frac{c I_{p}}{a_{1}^{2} T}\left(a b^{n}\right)\left(\frac{e^{a_{1}(T-M)}}{a_{1}}+M-\frac{1}{a_{1}}-T\right)
$$

Case (iv) $M^{*}<T$

$$
\begin{aligned}
& \text { Annual interest payable }=\frac{c I_{p}}{T} \int_{M}^{T_{w}} I_{R}(t) d t+\int_{M}^{T_{w}} I_{0}(t) d t+\int_{T_{w}}^{T} I(t) d t \\
& =\frac{c I_{p}}{T}\left(a b^{n}\right)\left[\left(e^{a_{1}(T-M)}-a_{1}\left(T_{w}-M\right)-1+\left(T_{w} T\right) a_{1}+\left(+\frac{1}{b_{1}}\left(e^{b_{1}\left(T_{w}-M\right)}-1-b_{1}\left(T_{w}-M\right)\right)\right)\right]\right.
\end{aligned}
$$

As described above, the annual total cost function can be expressed as $T C(T)=$ Ordering cost + stock - holding cost in $\mathrm{RW}+$ stock - holding cost in $\mathrm{OW}+$ purchasing cost + interest payable - interest earned

We have,

Case (I) $T_{a}<M$

$$
T C(T)= \begin{cases}T C_{1}(T) & \text { if } 0<T \leq T_{a} \\ T C_{2}(T) & \text { if } T_{a}<T \leq M \\ T C_{3}(T) & \text { if } M<T \leq M^{*} \\ T C_{4}(T) & \text { if } M^{*}<T\end{cases}
$$

where

$$
T C_{1}(T)=\frac{A}{T}+\frac{a b^{n}}{a_{1} T}\left[-\frac{u}{a_{1}}-u T-v\left(\frac{T}{a_{1}}+\frac{1}{a_{1}^{2}}\right)-\frac{v T^{2}}{2}+\frac{u e^{T}}{a_{1}}+\frac{v e^{a_{1} T}}{a_{1}^{2}}\right]+a b^{n} I_{e}\left(M-\frac{T}{2}\right)
$$




$$
\begin{aligned}
& T C_{2}(T)=\frac{A}{T}+\frac{a b^{n}}{b_{1} T}\left[\frac{x e^{b_{1} T_{w}}}{b_{1}}+\frac{y e^{b_{1} T_{w}}}{b_{1}^{2}}-\frac{x}{b_{1}}-x T_{w}-\frac{y T_{w}^{2}}{2}-\frac{y T_{w}}{b_{1}}-\frac{y}{b_{1}^{2}}\right]+\frac{u W}{T a_{1}} \\
& -\frac{u W e^{-a_{1} T_{w}}}{T a_{1}}-\frac{v W}{T}\left(\frac{T_{w} e^{-a_{1} T_{w}}}{a_{1}}+\frac{e^{-a_{1} T_{w}}}{a_{1}^{2}}\right)+\frac{v W}{T a_{1}^{2}}-\frac{u a b^{n}}{T a_{1}^{2}}-\frac{u a b^{n}}{a_{1}}+\frac{u a b^{n}}{T a_{1}^{2}}\left(e^{a_{1}\left(T-T_{w}\right)}\right)+\frac{u a b^{n} T_{w}}{T a_{1}}+ \\
& \frac{v a b^{n}}{T a_{1}}\left(-\frac{T}{a_{1}}-\frac{1}{a_{1}^{2}}+\frac{T_{w} e^{a_{1}\left(T-T_{w}\right)}}{a_{1}}+\frac{e^{a_{1}\left(T-T_{w}\right)}}{a_{1}^{2}}-T+T_{w}\right)+\frac{c}{T}\left(\frac{a b^{n}}{b_{1}}\left(e^{b_{1} T_{w}}-1\right)\right)-a b^{n} I_{e}\left(M-\frac{T}{2}\right) \\
& T C_{3}(T)=\frac{A}{T}+\frac{a b^{n}}{b_{1} T}\left[\frac{x e^{b_{1} T_{w}}}{b_{1}}+\frac{y e^{b_{1} T_{w}}}{b_{1}^{2}}-\frac{x}{b_{1}}-x T_{w}-\frac{y T_{w}^{2}}{2}-\frac{y T_{w}}{b_{1}}-\frac{y}{b_{1}^{2}}\right]+\frac{u W}{T a_{1}} \\
& -\frac{u W e^{-a_{1} T_{w}}}{T a_{1}}-\frac{v W}{T}\left(\frac{T_{w} e^{-a_{1} T_{w}}}{a_{1}}+\frac{e^{-a_{1} T_{w}}}{a_{1}^{2}}\right)+\frac{v W}{T a_{1}^{2}}-\frac{u a b^{n}}{T a_{1}^{2}}-\frac{u a b^{n}}{a_{1}}+\frac{u a b^{n}}{T a_{1}^{2}}\left(e^{a_{1}\left(T-T_{w}\right)}\right)+\frac{u a b^{n} T_{w}}{T a_{1}}+ \\
& \frac{v a b^{n}}{T a_{1}}\left(-\frac{T}{a_{1}}-\frac{1}{a_{1}^{2}}+\frac{T_{w} e^{a_{1}\left(T-T_{w}\right)}}{a_{1}}+\frac{e^{a_{1}\left(T-T_{w}\right)}}{a_{1}^{2}}-T+T_{w}\right)+\frac{c}{T}\left(\frac{a b^{n}}{b_{1}}\left(e^{b_{1} T_{w}}-1\right)\right)+ \\
& \frac{c I_{p}}{T}\left(\frac{a b^{n}}{a_{1}}\right)\left(\frac{e^{a_{1}(T-M)}}{a_{1}^{2}}+\frac{M_{1}}{a_{1}}-\frac{1}{a_{1}^{2}}-\frac{T}{a_{1}}\right)-\frac{a b^{n} I_{e} M^{2}}{2 T}
\end{aligned}
$$

And

$$
\begin{aligned}
& T C_{4}(T)=\frac{A}{T}+\frac{a b^{n}}{b_{1} T}\left[\frac{x e^{b_{1} T_{w}}}{b_{1}}+\frac{y e^{b_{1} T_{w}}}{b_{1}^{2}}-\frac{x}{b_{1}}-x T_{w}-\frac{y T_{w}^{2}}{2}-\frac{y T_{w}}{b_{1}}-\frac{y}{b_{1}^{2}}\right]+\frac{u W}{T a_{1}} \\
& -\frac{u W e^{-a_{1} T_{w}}}{T a_{1}}-\frac{v W}{T}\left(\frac{T_{w} e^{-a_{1} T_{w}}}{a_{1}}+\frac{e^{-a_{1} T_{w}}}{a_{1}^{2}}\right)+\frac{v W}{T a_{1}^{2}}-\frac{u a b^{n}}{T a_{1}^{2}}-\frac{u a b^{n}}{a_{1}}+\frac{u a b^{n}}{T a_{1}^{2}}\left(e^{a_{1}\left(T-T_{w}\right)}\right)+\frac{u a b^{n} T_{w}}{T a_{1}}+ \\
& \frac{v a b^{n}}{T a_{1}}\left(-\frac{T}{a_{1}}-\frac{1}{a_{1}^{2}}+\frac{T_{w} e^{a_{1}\left(T-T_{w}\right)}}{a_{1}}+\frac{e^{a_{1}\left(T-T_{w}\right)}}{a_{1}^{2}}-T+T_{w}\right)+\frac{c}{T}\left(\frac{a b^{n}}{b_{1}}\left(e^{b_{1} T_{w}}-1\right)\right)
\end{aligned}
$$

Fortunately, we obtain $\mathrm{T}_{\mathrm{w}}=0$ when $\mathrm{T}=\mathrm{T}_{\mathrm{a}}$ then the Eq. (10) implies $W=\frac{a b^{n}}{a_{1}}\left[e^{a_{1} T_{a}}-1\right]$ which results in $T C_{1}\left(T_{a}\right)=T C_{2}\left(T_{a}\right)$. Likewise, when $T=M^{*}$ then $T_{w}=M$ the Eq. (10) also implies $W e^{-a_{1} M}=\frac{a b^{n}}{a_{1}}\left[e^{a_{1}\left(M^{*}-T_{w}\right)}-1\right]$, which results $\quad$ in $T C_{3}\left(M^{*}\right)=T C_{4}\left(M^{*}\right) . \quad$ Besides, $\quad$ for $\quad \mathrm{T}=\mathrm{M}$ $T C_{2}(M)=T C_{3}(M)$. Therefore, TC $(\mathrm{T})$ is continuous and well defined on $\mathrm{T}>0$ in this case.

\section{Case(II) $T_{a} \geq M$}

$$
T C(T)= \begin{cases}T C_{1}(T) & \text { if } 0<T \leq M \\ T C_{2}(T) & \text { if } M<T \leq T_{a} \\ T C_{3}(T) & \text { if } T_{a}<T \leq M^{*} \\ T C_{4}(T) & \text { if } M^{*}<T\end{cases}
$$




$$
\begin{aligned}
& T C_{5}(T)=\frac{A}{T}+\frac{c}{a_{1} T}\left[a b^{n}\left(e^{a_{1} T}-1\right)\right]+\frac{a b^{n}}{T a_{1}}\left[\frac{-u}{a_{1}}-u T-v\left(\frac{T}{a_{1}}+\frac{1}{a_{1}^{2}}\right)-\frac{v T^{2}}{2}+\frac{u e^{T}}{a_{1}}+\frac{v e^{a_{1} T}}{a_{1}^{2}}\right] \\
& +\frac{\left(a b^{n}\right) I_{e} M^{2}}{2 T}+\frac{c I_{p}}{T}\left(\frac{e^{a_{1}(T-M)}}{a_{1}}+M-\frac{1}{a_{1}}-T\right)
\end{aligned}
$$

Likewise $\quad T C_{1}(M)=T C_{5}(M), T C_{5}\left(T_{a}\right)=T C_{3}\left(T_{a}\right)$ and $\quad T C_{3}\left(M^{*}\right)=T C_{4}\left(M^{*}\right)$ then $\quad \mathrm{TC}(\mathrm{T}) \quad$ is continuous and well defined on $\mathrm{T}>0$ in this case Eq. (23)

$$
\begin{aligned}
& T C_{1}^{\prime}(T)=-\frac{A}{T^{2}}-\frac{a b^{n}}{a_{1} T^{2}}\left[-\frac{u}{a_{1}}-u T-v\left(\frac{T}{a_{1}}+\frac{1}{a_{1}^{2}}\right)-\frac{v T^{2}}{2}+\frac{u e^{T}}{a_{1}}+\frac{v e^{a_{1} T}}{a_{1}^{2}}\right] \\
& +\frac{a b^{n}}{a_{1} T}\left[-u-v\left(\frac{1}{a_{1}}\right)-v T+\frac{u e^{T}}{a_{1}}+\frac{v e^{a_{1} T}}{a_{1}}\right]-\frac{a b^{n} I_{e}}{2}
\end{aligned}
$$

Fortunately, Lemmas 1-2 in Chung et al. (2001) implies that $T C_{1}^{\prime \prime}(T)>0$ for $\mathrm{T}>0$ and $T C_{5}^{\prime \prime}(T)>0$ for $T \geq M$ therefore, $T C_{1}(T)$ is convex on $(0, \infty)$ and $T C_{5}(T)$ is convex on $[M, \infty)$. Let $T_{j}^{*}$ denote the root of $T C_{j}^{\prime}(T)=0(\mathrm{j}=1$ and 5$)$ respectively in each case based on the convexity of $T C_{j}^{\prime}(T)=0(j=1$ and 5$)$ then

$$
\frac{d T C_{1}(T)}{d T} \begin{cases}<0 & \text { if } T \in\left(0, T_{1}^{*}\right) \\ =0 & \text { if } T=T_{1}^{*} \\ >0 & \text { if } T \in\left(T_{1}^{*}, \infty\right)\end{cases}
$$

and

$$
\frac{d T C_{5}(T)}{d T} \begin{cases}<0 & \text { if } T \in\left[M, T_{5}^{*}\right) \\ =0 & \text { if } T=T_{5}^{*} \\ >0 & \text { if } T \in\left(T_{5}^{*}, \infty\right)\end{cases}
$$

The above equations imply that (i) $\mathrm{TC}_{1}(\mathrm{~T})$ is decreasing on $\left(0, T_{1}^{*}\right]$ and increasing on $\left[T_{1}^{*}, \infty\right)$ and (ii) $\mathrm{TC}_{5}(\mathrm{~T})$ is decreasing on $\left[M, T_{5}^{*}\right]$ and increasing on $\left[T_{5}^{*}, \infty\right)$

On the other hand, the necessary condition for minimizing $\mathrm{TC}_{\mathrm{i}}(\mathrm{T})(\mathrm{i}=2,3 \& 4)$ is that the first derivate of $\mathrm{TC}_{\mathrm{i}}(\mathrm{T})(\mathrm{i}=2,3 \& 4)$ is zero respectively. Furthermore $\mathrm{TC}_{\mathrm{i}}(\mathrm{T})(\mathrm{i}=2,3 \& 4)$ holds if and only if the right side of equation (28) is equal to zero.

\section{Algorithm}

Step 1: If $T_{a}<M$ then calculate $T C_{1}(T), T C_{2}(T), T C_{3}(T)$ and $T C_{4}(T)$

Step 2: Evaluate $T C_{1}(T), T C_{2}(T), T C_{3}(T), T C_{4}(T)$ and $T C_{5}(T)$ If $T_{a} \geq M$ 
Step 3: To check $\frac{d T C_{1}(T)}{d T}\left\{\begin{array}{ll}<0 & \text { if } T \in\left(0, T_{1}^{*}\right) \\ =0 & \text { if } T=T_{1}^{*} \\ >0 & \text { if } T \in\left(T_{1}^{*}, \infty\right)\end{array}\right.$ also $\frac{d T C_{5}(T)}{d T} \begin{cases}<0 & \text { if } T \in\left[M, T_{5}^{*}\right) \\ =0 & \text { if } T=T_{5}^{*} \\ >0 & \text { if } T \in\left(T_{5}^{*}, \infty\right)\end{cases}$

Step 4: to check (i) $\mathrm{TC}_{1}(\mathrm{~T})$ is decreasing on $\left(0, T_{1}^{*}\right]$ and increasing on $\left[T_{1}^{*}, \infty\right)$ and (ii) $\mathrm{TC}_{5}(\mathrm{~T})$ is decreasing on $\left[M, T_{5}^{*}\right]$ and increasing on $\left[T_{5}^{*}, \infty\right)$

Step 5: Analyzed the first derivative of $\mathrm{TC}_{\mathrm{i}}(\mathrm{T})(\mathrm{i}=2,3 \& 4)$ is equal to zero.

Step 6: Stop

After obtaining the optimal values of TC and T, the optimal order quantity Q can be obtained from $Q=I_{R}(0)+I_{01}(0)$

\section{Numerical Examples}

In this area, we give the numerical case to represent the model plan. Moreover, to ponder the impacts of changes in the framework parameters $\mathrm{W}$, and request on the ideal recharging time interim $\mathrm{T}^{*}$, the ideal request amount $\mathrm{Q}$ and the base aggregate applicable cost per unit time $\mathrm{TC}\left(\mathrm{T}^{*}\right)$ of the accompanying information are created.

Table 1

Results for example 1

\begin{tabular}{ccccccc}
\hline $\mathbf{A}$ & $\mathbf{T}_{\mathbf{a}}$ & $\mathbf{M}^{*}$ & $T_{j}^{*}$ & $\mathbf{T}^{*}$ & $\mathbf{T C}\left(\mathbf{T}^{*}\right)$ & Use RW \\
\hline $\mathbf{4 5 0}$ & 0.2865 & 0.5723 & $T_{4}^{*}$ & 0.5984 & 5983.12 & Yes \\
$\mathbf{1 0 0}$ & 0.2865 & 0.5723 & $T_{3}^{*}$ & 0.3036 & 5126.35 & Yes \\
$\mathbf{7 0}$ & 0.2865 & 0.5723 & $T_{2}^{*}$ & 0.2889 & 5097.64 & Yes \\
$\mathbf{5 0}$ & 0.2865 & 0.5723 & $T_{1}^{*}$ & 0.2430 & 5024.10 & No \\
\hline
\end{tabular}

Table 2

The results for sensitivity analysis of example 1

\begin{tabular}{cccccccc}
\hline $\mathbf{W}$ & $\mathbf{A}$ & $\mathbf{T}_{\mathbf{a}}$ & $\mathbf{M}^{*}$ & $T_{j}^{*}$ & $\mathbf{T}^{*}$ & $\mathbf{T C}\left(\mathbf{T}^{*}\right)$ & Use RW \\
\hline $\mathbf{1 5 0}$ & 50 & 0.2865 & 0.5723 & $T_{1}^{*}$ & 0.2430 & 5024.10 & No \\
$\mathbf{1 5 0}$ & 100 & 0.2865 & 0.5723 & $T_{3}^{*}$ & 0.3256 & 5182.21 & Yes \\
$\mathbf{1 5 0}$ & 150 & 0.2865 & 0.5723 & $T_{3}^{*}$ & 0.3841 & 5371.00 & Yes \\
$\mathbf{5 0}$ & 50 & 0.0894 & 0.3842 & $T_{2}^{*}$ & 0.1925 & 5011.32 & Yes \\
$\mathbf{1 0 0}$ & 50 & 0.1845 & 0.4587 & $T_{2}^{*}$ & 0.2221 & 5008.35 & Yes \\
$\mathbf{1 5 0}$ & 50 & 0.2865 & 0.5723 & $T_{1}^{*}$ & 0.2434 & 4999.89 & No \\
$\mathbf{1 5 0}$ & 50 & 0.2865 & 0.5723 & $T_{1}^{*}$ & 0.2434 & 4999.89 & No \\
$\mathbf{1 5 0}$ & 50 & 0.2028 & 0.5110 & $T_{2}^{*}$ & 0.2014 & 6878.39 & Yes \\
$\mathbf{1 5 0}$ & 50 & 0.1543 & 0.4362 & $T_{2}^{*}$ & 0.1752 & 8630.12 & Yes \\
\hline
\end{tabular}


Table 3

Results for example 2

\begin{tabular}{ccccccc}
\hline $\mathbf{A}$ & $\mathbf{W}$ & $\mathbf{T}_{\mathbf{a}}$ & $\mathbf{M}^{*}$ & $T_{j}^{*}$ & $\mathbf{T}^{*}$ & $\left.\mathbf{T C}^{*} \mathbf{T}^{*}\right)$ \\
\hline 50 & 50 & 0.4725 & 0.6984 & $T_{4}^{*}$ & 0.6963 & 564.281 \\
30 & 50 & 0.4725 & 0.6984 & $T_{3}^{*}$ & 0.6027 & 559.183 \\
20 & 50 & 0.4725 & 0.6984 & $T_{5}^{*}$ & 0.4523 & 515.421 \\
10 & 50 & 0.4725 & 0.6984 & $T_{1}^{*}$ & 0.2658 & 495.486 \\
\hline
\end{tabular}

\section{Table 4}

The results for sensitivity analysis of example 2

\begin{tabular}{ccccccc}
\hline $\mathbf{A}$ & $\mathbf{W}$ & $\mathbf{T}_{\mathbf{a}}$ & $\mathbf{M}^{*}$ & $T_{j}^{*}$ & $\mathbf{T}^{*}$ & $\left.\mathbf{T C}^{*} \mathbf{c}\right)$ \\
\hline $\mathbf{5 0}$ & 50 & 0.4725 & 0.6924 & $T_{4}^{*}$ & 0.6963 & 564.281 \\
$\mathbf{5 0}$ & 50 & 0.3742 & 0.6421 & $T_{3}^{*}$ & 0.6158 & 724.158 \\
$\mathbf{5 0}$ & 50 & 0.3265 & 0.5932 & $T_{3}^{*}$ & 0.5764 & 852.312 \\
$\mathbf{5 0}$ & 60 & 0.5845 & 0.8520 & $T_{2}^{*}$ & 0.7993 & 550.000 \\
$\mathbf{5 0}$ & 50 & 0.4725 & 0.6924 & $T_{4}^{*}$ & 0.6963 & 564.281 \\
$\mathbf{5 0}$ & 40 & 0.3854 & 0.6258 & $T_{4}^{*}$ & 0.6520 & 570.300 \\
\hline
\end{tabular}

\section{Example 1:}

Let $\mathrm{u}=\$ 1 /$ unit $/$ year, $\mathrm{v}=\$ 1 /$ unit/year, $\mathrm{x}=\$ 2 /$ unit/year, $\mathrm{y}=\$ 1 /$ unit/year, $\mathrm{W}=150, \mathrm{a}=50, \mathrm{~b}=10, \mathrm{n}=$ $0,1,2, \ldots, \mathrm{M}=0.3$ year, $\mathrm{c}=\$ 10 /$ unit /year, $\mathrm{a}_{1}=0.03, \mathrm{~b}_{1}=0.05, \mathrm{I}_{\mathrm{P}}=15 \%, \mathrm{I}_{\mathrm{e}}=12 \%$ and $\quad \mathrm{s}=\$ 15 /$ unit/year. The result is summarized in Table 1 and 2 .

\section{Example 2:}

Let $\mathrm{u}=\$ 0.2 /$ unit $/$ year, $\mathrm{v}=\$ 0.1 /$ unit /year, $\mathrm{x}=\$ 0.3 /$ unit/year, $\mathrm{y}=\$ 0.2 /$ unit/year, $\mathrm{M}=0.3$ year, $\mathrm{a}_{1}=$ $0.02, \mathrm{~b}_{1}=0.05, \mathrm{I}_{\mathrm{P}}=15 \%, \mathrm{I}_{\mathrm{e}}=12 \%$ and $\mathrm{s}=\$ 20 /$ unit/year. The result is summarized in Tables (3-4).

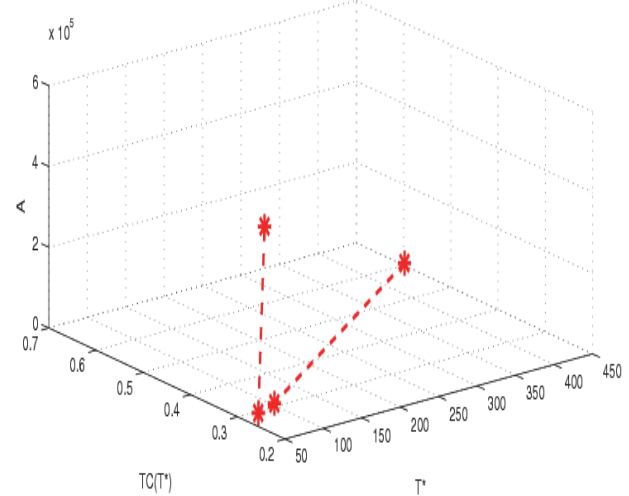

Fig(a) Graphical Representation for Table 1

Variation of optimal cost $\mathrm{TC}\left(\mathrm{T}^{*}\right)$ with respect to $\mathrm{T}$ and $\mathrm{A}$

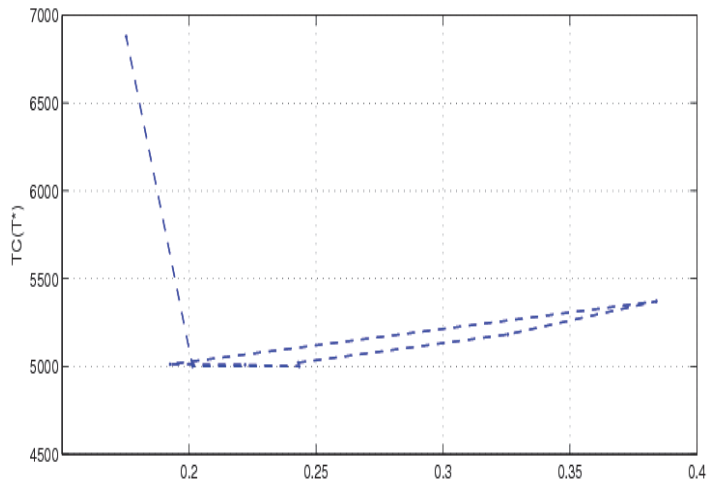

Fig(b) Graphical Representation for Table 2

Variation of optimal cost $\mathrm{TC}\left(\mathrm{T}^{*}\right)$ with respect to $\mathrm{T}$ 


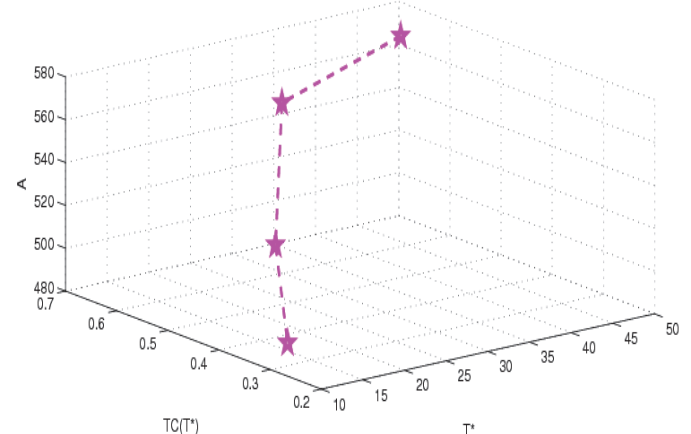

Fig(c) Graphical Representation for Table 3

Variation of optimal cost $\mathrm{TC}\left(\mathrm{T}^{*}\right)$ with respect to $\mathrm{T}$ and $\mathrm{A}$

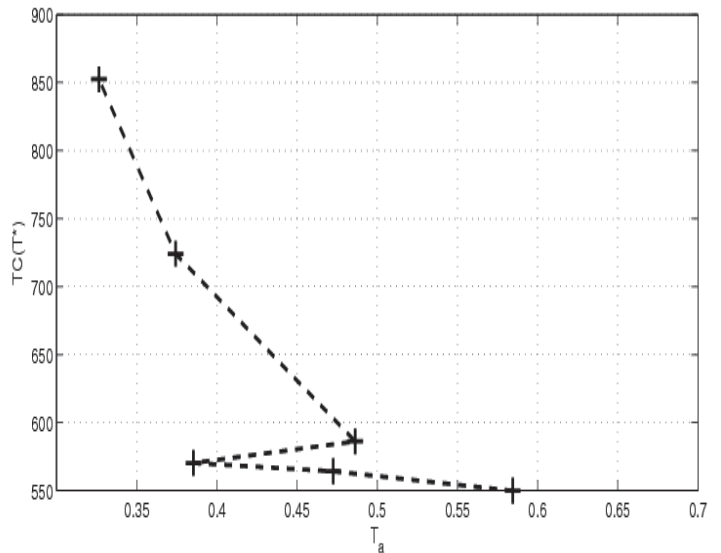

Fig(d) Graphical Representation for Table 4

Variation of optimal cost $\mathrm{TC}\left(\mathrm{T}^{*}\right)$ with respect to $\mathrm{T}$

\section{Observation}

On the premise of the outcomes appeared in Table 1-4, the principle conclusions are as per the following:

1. As the estimation of the renewal cost per arrange (A) builds, the ideal time interim $T^{*}$ and the base aggregate pertinent cost per unit time TC $\left(\mathrm{T}^{*}\right)$ will be expanded. It inferred that if the requesting cost per request could be diminished viably, the aggregate significant cost per unit time could be made strides.

2. An increment in the estimation of $\mathrm{W}$ will bring about an expansion in $\mathrm{T}^{*}$, however, diminish in $\mathrm{TC}\left(\mathrm{T}^{*}\right)$. This implies the estimation of $\mathrm{W}$ expands, the retailer ought to build the requesting renewal time interim. Additionally the base aggregate cost per unit time will be diminished.

3. As the estimation of interest expands, the retailer needs to arrange a greater request amount, as is the base aggregate cost per unit time. Likewise the ideal renewal time interim will be expanded.

4. A diminishing in the estimation of $\mathrm{M}^{*}$ will brings about an expansion in $\mathrm{TC}\left(\mathrm{T}^{*}\right)$, however diminish in $\mathrm{T}^{*}$. That is the estimation of $\mathrm{M}^{*}$ reductions, the ideal time interim will be increments. Additionally the base aggregate cost per unit time will be diminished.

\section{Conclusion}

This paper has managed the deterministic request level stock model for decaying things with limited distribution center limit and addressed the status of reasonable postponement in installments. The above inductions have demonstrated that the ideal arrangements exist as well as exceptional and presented the ideal arrangement methodology to discover the recharging strategies. From these outcomes the chief of stock framework can undoubtedly choose whether to utilize the leased distribution center to hold mush more things. Holding expenses and weakening expenses were diverse in OW and RW because of various safeguarding situations. To diminish the stock costs, it would be efficient for firms to store merchandise in OW before RW, and clear the stocks in RW before OW. By developing a proficient computer calculation, we showed through a couple of numerical illustrations that how the ideal 
aggregate cost could be determined. Moreover, affectability examination was completed as for the key parameters and helpful administrative experiences are getting. The graphical representations are additionally given to break down the effectiveness of demonstrating obviously.

There are a few expansions of this work, which could constitute future research related to this field. One quick, plausible expansion could be to examine the steady request to a more summed up request design that varies with cost, stock level, time and their mix. Another conceivable augmentation of this work may be led by considering two unique sorts of installment technique in the exchange credit approach. Besides, the model may permit the deficiencies, halfway multiplying, amount rebates, exponentially expanding, holding costs, various things with fractional accumulating and changing the request as cubic.

\section{Acknowledgements}

The authors would like to thank the editors and anonymous reviewers for their valuable and constructive comments, which have led to a significant improvement in the manuscript.

This research was fully supported by the National Board for Higher Mathematics, Government of India under the scheme of NBHM research project with 2/48(9)/2013/NBHM(R.P)/R\&D II /Dated 16.01.2014.

\section{References}

Abou-El-Ata, M. O., \& Kotb, K. A. M. (1997). Multi-item EOQ inventory model with varying holding cost under two restrictions: a geometric programming approach. Production planning \& control, 8(6), 608-611.

Alfares, H. K. (2007). Inventory model with stock-level dependent demand rate and variable holding cost. International Journal of Production Economics, 108(1), 259-265.

Anand \& Kapil, K.B. (2013). Modeling of an inventory system for decaying items with time dependent demand rate under permissible delay. International Journal of Advanced Research in Computer Science and Software Engineering, 3,786-793.

Baker, R. C., \& Urban, T. L. (1988). A deterministic inventory system with an inventory-leveldependent demand rate. Journal of the Operational Research Society, 823-831.

Bera, S., Kar, S., Chakraborti, T., \& Sinha, B. K. (2014). An inventory model for deteriorating items under conditionally permissible delay in payments depending on the order quantity. Applied Mathematics, 5(17), 2675.

Bhathavala, P. H., \& Rathod, K. D. (2012). Inventory model with stock-level dependent demand rate and quantity based holding cost. International Journal of Engineering Research \& Technology (IJERT), 1,1-6.

Chang, C. T. (2016). Inventory models with stock-and pricedependent demand for deteriorating items based on limited shelf space. Yugoslav Journal of Operations Research, 20(1), 55-69.

Chen, L. H., \& Kang, F. S. (2010). Integrated inventory models considering permissible delay in payment and variant pricing strategy. Applied Mathematical Modelling, 34(1), 36-46.

Chowdhury, R. R., Ghosh, S. K., \& Chaudhuri, K. S. (2017). An optimal inventory replenishment policy for a perishable item with time quadratic demand and partial backlogging with shortages in all cycles. International Journal of Applied and Computational Mathematics, 3(2), 1001-1017.

Chung, K.J. Chang, S.L., \& Yang, W.D. (2001). The optimal cycle time for exponential products under trade credit. The Engineering Economist, 46, 232-242.

Dash, B. P., Singh, T., \& Pattnayak, H. (2014). An inventory model for deteriorating items with exponential declining demand and time-varying holding cost. American Journal of Operations Research, 4(01), 1-7. 
Debata, S., \& Acharya, M. (2017). An inventory control for non-instantaneous deteriorating items with non-zero lead time and partial backlogging under joint price and time dependent demand. International Journal of Applied and Computational Mathematics, 3(2), 1381-1393.

Geetha, K. V., \& Udayakumar, R. (2016). Optimal lot sizing policy for non-instantaneous deteriorating items with price and advertisement dependent demand under partial backlogging. International Journal of Applied and Computational Mathematics, 2(2), 171-193.

Liao, J. J. (2007). On an EPQ model for deteriorating items under permissible delay in payments. Applied Mathematical Modelling, 31(3), 393-403.

Liao, J. J. (2007). A note on an EOQ model for deteriorating items under supplier credit linked to ordering quantity. Applied Mathematical Modelling, 31(8), 1690-1699.

Hu, F., \& Liu, D. (2010). Optimal replenishment policy for the EPQ model with permissible delay in payments and allowable shortages. Applied Mathematical Modelling, 34(10), 3108-3117.

Huang, Y. F. (2016). An EPQ model under cash discount and permissible delay in payments derived without derivatives. Yugoslav Journal of Operations Research, 17(2)

Jinn,T. T. and Liang,Y. O. (2005), An EOQ Model for Deteriorating Items with Power-Form StockDependent Demand, Information and Management Sciences, Vol. 16,1-16.

Joaquín, S., Manuel González,-D.1..R., Jaime Febles,A. and David Alcaide,L.P. (2014), An inventory model for deteriorating items with shortages and time-varying demand, International Journal of Production Economics, Vol. 155, 155- 162.

Joaquín, S., Manuel González,-D.1..R., Jaime Febles,A. and David Alcaide,L.P., Optimal policy for an inventory system with power demand, backlogged shortages and production rate proportional to demand rate, International Journal of Production Economics, Vol. 155,163-171.

Kasthuri, R., \& Seshaiah, C. V. (2014). Multi-item inventory lot-size model with increasing varying holding cost:A Karush-Kuhn-Tucker conditions approach. International Journal of Mathatical Analysis, 8, $157-165$.

Kotb, K. A. M., \& Fergany, H. A. (2011). Multi-item EOQ model with varying holding cost: A geometric programming approach. International Mathematical Forum, 6(23), 1135 - 1144.

Li, J., Feng, H., \& Zeng, Y. (2014). Inventory games with permissible delay in payments. European Journal of Operational Research, 234(3), 694-700.

Mishra, U. (2016). An EOQ model with time dependent Weibull deterioration, quadratic demand and partial backlogging. International Journal of Applied and Computational Mathematics, 2(4), $545-$ 563.

Mishra, U. (2016). An Inventory Model for Weibull Deterioration with Stock and Price Dependent Demand. International Journal of Applied and Computational Mathematics, 1-17.

Musa, A., \& Sani, B. (2012). Inventory ordering policies of delayed deteriorating items under permissible delay in payments. International Journal of Production Economics, 136(1), 75-83.

Patel, R., \& Sheikh, S. R. (2015). Inventory Model with Different Deterioration Rates under Linear Demand and Time Varying Holding Cost. International J. Mathematics and Statistics Invention, 3(6), 36-42.

Raman, P. and Reena, U.P. (2014), Inventory model for Weibull deteriorating items with stock dependent demand, time varying holding cost and variable selling price. Indian Journal Of Applied Research, 4, 577-580.

Shukla, D., Chandel, R. P. S., Khedlekar, U. K., \& Agrawal, R. K. (2010). Multi-items inventory model with time varying holding cost and variable deterioration. Canadian Journal on Computing in Mathematics, Natural Sciences, Engineering \& Medicine, 1(8), 223-227.

Sharmila, D., \& Uthayakumar, R. (2015). Inventory model for deteriorating items with quadratic demand, partial backlogging and partial trade credit. Operations Research and Applications: An International Journal (ORAJ), 2, 51-70.

Sharmila, D., \& Uthayakumar, R. (2015). Inventory model for deteriorating items involving fuzzy with shortages and exponential demand. International Journal of Supply and Operations Management, 2(3), 888. 
Sharmila, D., \& Uthayakumar, R. (2016). Optimal inventory model for deteriorating products with Weibull distribution deterioration, stock and time-dependent demand, time-varying holding cost under fully backlogging. Communications in Applied Analysis, 20, 277-290.

Sharmila, D., \& Uthayakumar, R. (2016). An inventory model with three rates of production rate under stock and time dependent demand for time varying deterioration rate with shortages. International Journal of Advanced Engineering, Management and Science (IJAEMS), 2, 1595-1602.

Shah, N. H., Chaudhari, U., \& Jani, M. Y. (2017). Optimal policies for time-varying deteriorating item with preservation technology under selling price and trade credit dependent quadratic demand in a supply chain. International Journal of Applied and Computational Mathematics, 3(2), 363-379.

Soni, H. N. (2013). Optimal replenishment policies for deteriorating items with stock sensitive demand under two-level trade credit and limited capacity. Applied Mathematical Modelling, 37(8), $5887-$ 5895.

Teng, J., \& Yang, H. (2007). Deterministic inventory lot-size models with time-varying demand and cost under generalized holding costs. International journal of information and management sciences, 18(2), 113.

Tripathi, R. (2013). Inventory model with different demand rate and different holding cost. International Journal of Industrial Engineering Computations, 4(3), 437-446.

Tripathy, C. K., \& Pradhan, L. M. (2010). An EOQ model for Weibull deteriorating items with power demand and partial backlogging. International Journal of Contemporary Mathematical Sciences, 5(38), 1895-1904.

Tripathi, R. P., Misra, S. S., \& Shukla, H. S. (2010). A cash flow oriented EOQ model under permissible delay in payments. International Journal of Engineering, Science and Technology, 2(11), 123-131.

Tripathi, R. P., Pareek, S., \& Kaur, M. (2017). Inventory Model with Exponential Time-Dependent Demand Rate, Variable Deterioration, Shortages and Production Cost. International Journal of Applied and Computational Mathematics, 3(2), 1407-1419.

Tripathi, R. P. (2016). Optimal Ordering Policy for Deteriorating Items Under Price Sensitive Demand Scheme. International Journal of Applied and Computational Mathematics, 1-17.

Ukil, S. I., Islam, M. E., \& Uddin, M. S. (2015). A Production Inventory Model of Power Demand and Constant Production Rate Where the Products Have Finite Shelf-Life. Journal of Service Science and Management, 8(06), 874.

Vipin, K., Gopal, P., \& Gupta, C.B. (2013). A deterministic inventory model for deteriorating items with selling price dependent demand and parabolic time varying holding cost under trade credit. International Journal of Soft Computing and Engineering (IJSCE), 3, 33-37.

Vinod, K. M., Lal, S. S., \& Rakesh, K. (2013). An inventory model for deteriorating items with timedependent demand and time-varying holding cost under partial backlogging. Journal of Industrial Engineering International, 9, 1-5.

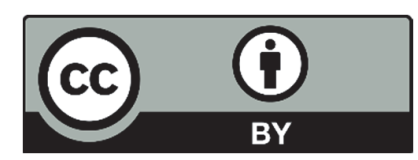

(C) 2018 by the authors; licensee Growing Science, Canada. This is an open access article distributed under the terms and conditions of the Creative Commons Attribution (CC-BY) license (http://creativecommons.org/licenses/by/4.0/). 